\title{
Designing with learning myths in mind
}

\author{
Jay Sloan-Lynch, PhD
}

Boulder, $\mathrm{CO}$

Contact: jay.lynch@colorado.edu 


\begin{abstract}
Education is notorious for its quick embrace of unproven learning and teaching practices. Popular theories like learning styles, multiple intelligences, and hemispheric dominance pervade commercial educational products, teaching curricula, and professional development programs, despite their scientifically dubious status. And recent surveys of educators, across a wide range of countries and cultures, reveal endorsement levels approaching or exceeding $85 \%$ for many of these learning myths. Extending this work, we employed Bayesian estimation to estimate endorsement levels for several popular learning myths among an increasingly influential and growing segment in education: instructional designers. While our findings suggest slightly lower myth endorsement levels among instructional designers, our data and model still predict overall endorsement levels for several popular learning myths to be greater than $70 \%$ with .90 probability. Given the continued popularity of learning myths, despite more than a decade of concerted debunking efforts, we conclude this article with some observations that may suggest a more fruitful way forward when it comes to challenging their enduring appeal.
\end{abstract}

Keywords: learning styles; neuromyths; learning myths; instructional design; Bayesian estimation 


\section{Designing with learning myths in mind}

For decades, learning scientists have lamented the failure of education research to meaningfully impact the practice of education. Studies consistently show a lack of awareness on the part of students and educators regarding effective learning strategies and instructional methods (see, e.g., Bjork, Dunlosky, \& Kornell, 2013; Karpicke, Butler, \& Roediger, 2009; Kornell \& Bjork, 2007). Additionally, the popularity of empirically unsupported learning myths continue to hinder the expansion of evidence-informed practice in education (Dekker, Lee, Howard-Jones, \& Jolles, 2012; De Bruyckere, Kirschner, \& Hulshof, 2015). While many of these myths have their origins in laudable efforts by educators to differentiate instruction or incorporate recent findings in neuroscience, they also reflect serious scientific misunderstandings and are unsubstantiated by credible research. While many learning myths pervade education, several enjoy particular notoriety.

Consider the widespread belief in learning styles. Theories of learning styles rest on two fundamental claims. First, there exist identifiable and robust learner preferences for perceiving or processing information that can be used to classify students into distinct learning style groups. The detection of these learner preferences is typically achieved through self-report questionnaires that query learners about the instructional methods or modalities they believe enable them to learn best. And second, students learn most effectively when instructional methods are tailored to their preferred learning style and less effectively otherwise. That is, learners who prefer receiving information in a visual modality are said to learn most successfully when they experience instruction emphasizing images and less well when instruction relies 
primarily on verbal explanations (Kirschner \& Merriënboer, 2013). Although intuitively compelling to many, there is little empirical support for the educational efficacy of tailoring instruction to students' preferred learning styles (Kirschner, 2017). Scholarly reviews of learning styles research indicate a shocking absence of evidentiary support for matching instructional methods to students' learning style preferences (Pashler, McDaniel, Rowher, \& Bjork, 2009). And an exhaustive examination of the available learning styles literature concluded that proponents of learning styles have systematically failed to employ the type of experimental designs required to justify claims of pedagogical improvement (Coffield, Moseley, \& Ecclestone, 2004).

Another popular learning myth is based on a misunderstanding of brain lateralization research, which has led to an erroneous belief in the existence right brain/left brain dominant learners. Whereas left brain thinkers are believed to prioritize logic, reason, and writing, right brain thinkers are claimed to prefer to think in more creative, artistic, and abstract ways. This misinterpretation has led many in education to suggest there is learning value in tailoring instruction to students' dominant thinking preferences (e.g., Hoffman, 2002; Siegel \& Bryson, 2012). And many commercialized teaching programs and diagnostic tools have arisen to aid teachers in identifying students' preferred brain hemisphere. The popularity of right brain/left brain learners has persisted despite vociferous denunciations from the neuroscience community stating no such cognitive dichotomy exists and that any complex mental activity relies on both hemispheres working closely in tandem (Corballis, 2007; Geake, 2008). Empirical studies using brain imaging have also convincingly demonstrated that people's thinking is not dominated by a single hemisphere (Nielsen, Zielinski, Ferguson, Lainhart, \& Anderson, 2013). 
The enthusiastic adoption of multiple intelligences theory in education is another example of an unfortunate learning myth. Originally hypothesized by Howard Gardner, multiple intelligences theory posits that rather than single dominant intelligence, human intelligence can be subdivided into eight or more autonomous subintelligences that operate in different parts of the brain (1983). Gardner has suggested that despite this multitude of disparate intelligence types, only linguistic and logical-mathematical intelligences are typically tested and taught in schools, thereby disadvantaging students with other intelligence strengths. Consequently, proponents of multiple intelligence theory claim that maximizing each student's potential requires identifying his or her unique intelligence strengths and then designing learning experiences that take these into account (e.g., Armstrong, 2009; Gardner, 2013, Kornhaber, Fierros, \& Veenema, 2003). However, empirical support for the psychological validity and educational value of multiple intelligences theory is virtually nonexistent, and the theory conflicts with well-established theories of the mind (see, Howard-Jones, 2014; Waterhouse, 2006; Willingham, 2004).

Finally, various incarnations of the 'learning pyramid' myth are ubiquitous in education. Perhaps the most common version of this myth involves a visualization associated with the National Training Laboratories (NTL) ostensibly indicating expected learner retention percentages associated with various teaching strategies (see Figure 1). For example, the pyramid suggests that instruction involving reading as the primary teaching activity results in students retaining only $10 \%$ of information, whereas instruction that involves students engaging in group discussion supports retention levels closer to $50 \%$. The simplicity of the diagram, as well as its apparent confirmation of most educators' intuitive preference for more active learning strategies, 
makes this visualization

extremely compelling. However, the retention percentages associated with the learning pyramid are not supported by empirical evidence (see, Lalley \& Miller, 2007; Letrud, 2012; Subramony, Molenda, Betrus, \&

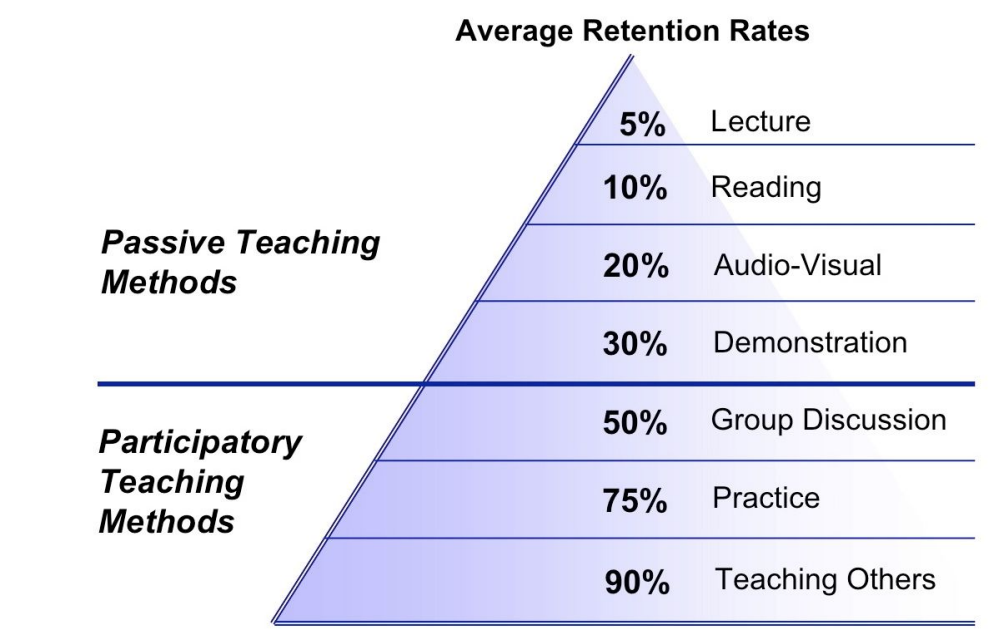
*Adapted from National Training Laboratories. Bethel, Maine Figure 1.

Thalheimer, 2014) and it reflects a common misconception that learning involving physical activity is inherently more effective than behaviorally passive learning activities such as listening intently to a lecture (Clark \& Mayer, 2008). Furthemore, the numbers supporting these claims are uninterpretable without relevant contextual information, such as method of measurement, instructional content, retention delay, etc. (De Bruychkere et al., 2015).

\section{Prevalence of Learning Myths}

Despite the lack of empirical evidence for these and other learning myths, the prevalence of learning myths is shockingly widespread among educators and the general public. Surveys consistently find that greater than $85 \%$ of pre and in-service teachers in the UK and Netherlands agree with many popular learning myths, including learning styles and hemispheric dominance (Dekker et al., 2012; Tardif, Doudin, \& Meylan, 2015), and polls of the general public in the United States reveal endorsement levels close to $90 \%$ for some learning myths (Boser, 2017; Macdonald, Germine, Anderson, Chistodoulou, \& McGrath, 2017). Surveys conducted by 
researchers from around the world, with students and educators from a variety of cultures, have replicated these findings, observing comparable learning myth endorsement levels in Spain (Ferrero, Garaizar, \& Vadillo, 2016), Greece (Papadatou-Pastou, Haliou, \& Vlachos, 2017), China (Pei, Howard-Jones, Zhang, Liu, \& Jin, 2015), Portugal (Rato, Abreu, \& Castro-Caldes, 2013), and Turkey (Karakus, Howard-Jones, \& Jay, 2015). Even more worrisome, several studies have found that the more educators are interested in and knowledgeable about general neuroscience, the more susceptible they are to common learning myths tied to the brain (Dekker et al., 2012; Ferrero, Garaizar, \& Vadillo, 2016; Gleichgerrcht, Lira Luttges, Salvarezza, \& Campos, 2015).

The prevalence of learning myths is also evident at an institutional level. A recent survey of 39 US Higher Education institutions, for instance, revealed that 29 (72\%) taught learning styles as part of their online faculty development (Meyer and Murrell, 2014). And many US college and university teaching centers provide resources to aid students and faculty in identifying learners' optimal learning or studying style (Dandy \& Bendersky, 2014).

While troubling, these findings are not terribly surprising. Much like political fake news, learning myths are particularly virulent because they: 1) confirm many people's pre-existing biases and beliefs about learning, 2) sound plausible because they rely on kernels of scientific truth, and 3) provide simple solutions/explanations for complex phenomena. Furthermore, educators face a deluge of commercial interests intent on creating an air of legitimacy for learning myths, including sponsored conferences, popular books, 'validated' measurement instruments, and hands-on workshops (Coffield et al., 2004; Goswami, 2006). But while the 
prevalence of learning myths among educators is relatively well-known, we have less insight into the prevalence of learning myths among other professionals involved in education.

\section{Scope of the Present Study}

Previous studies investigating the prevalence of learning myths have focused primarily on educators and pre-service teachers. And although educators are well-versed in their area of expertise, rarely do they receive exposure to research in the science of instruction and learning (see, Pomerance, Greenberg, \& Walsh, 2016). Consequently, it might be wondered whether professionals whose job is to create effective learning experiences are equally likely to endorse popular learning myths. A growing number of universities, schools, and companies now employ instructional designers whose job and educational background are specifically geared toward the design of evidence-informed instruction. In particular, a growing number of higher education institutions now employ instructional designers who collaborate with faculty on the design and development of courses and who provide guidance on effective academic technologies and research-based teaching strategies. Given this important advisory role, it might be wondered to what extent instructional designers endorse popular learning myths and whether their education and experience helps inoculate them from these false beliefs.

Thus the primary purpose of the present study was to estimate endorsement levels for several popular learning myths among instructional designers and compare these estimates with those previously found among educators and the general public. A second goal of the study was to explore relationships between learning myth endorsement and various professional characteristics of instructional designers. 


\section{Materials and Methods}

\section{Participants}

The total sample of 69 participants included instructional designers working in both higher education and corporate training. Participants were geographically dispersed throughout the United States. All participants had earned at least a bachelor's degree, with the most common degrees being earned in the fields of education (27.5\%), instructional/educational technology (26.1\%), and instructional design (16\%). A majority of participants had 2-15 years of instructional design experience (79.7\%), with (11.6\%) having more than 15 years and $(8.7 \%)$ having less than two years. 65 percent of participants had experience teaching either face-to-face or online at the post-secondary level. And most instructional designers reported keeping up-to-date on current learning research "Somewhat" (49.3\%), with fewer reporting "A little" $(20.3 \%)$ or "A lot" (30.4\%); zero participants reported not keeping up on learning research at all.

\section{Procedure}

Instructional designers were contacted to participate via email invitation, by personal invitation, or approached at a national education conference. The questionnaire was created and hosted on SurveyMonkey® and a link was emailed to participants along with information about the study. The survey was sent to a total of 109 instructional designers and 72 surveys were successfully submitted. Three of the submitted surveys included only answers to demographic questions, however, and thus were excluded from further analysis, resulting in the final sample size of 69 . The research project was presented to the participants as a survey about effective learning design methods. Completion of the questionnaire required approximately 20 minutes 
and participants were informed at the beginning of the survey that their data would be processed anonymously and no personally identifiable information was collected.

\section{Materials}

The survey consisted of two parts. In the first section, participants gave their informed consent and were introduced to the purpose of the study. They provided background information about their professional qualifications (e.g., highest degree earned), years of instructional design experience, and post-secondary teaching experience. Participants also indicated how much they try to keep up-to-date on research in the learning sciences and the extent to which they felt they were able to apply learning research in their work. Finally, participants were asked an open-ended question about what innovation they believed would have the most positive impact on education in the next five years.

In the second part of the survey, participants answered twenty-four questions related to learning and education research. These questions included four statements about learning myths, two written by Dekker et al., (2012) addressing belief in learning styles and hemispheric dominance, and two written by the present author on multiple intelligence theory and the learning pyramid (see Table 1). These learning myths were interleaved with 20 statements written by the present author covering various topics in multimedia learning theory (e.g., "Presenting the same material simultaneously in both auditory and visual modalities improves learner retention.") and educational psychology (e.g., "Retention of material is greater if study sessions are spaced out rather than massed.”). Participants were instructed to respond to each statement by selecting either "agree," "disagree," or "not sure." All the learning myths were false 
statements, whereas the questions about learning research consisted of both true and false statements. The number of correct and incorrect statements were evenly balanced.

\section{Data Analysis}

Given the primary research goal was to infer plausible values for learning myth endorsement levels among instructional designers, we employed Bayesian estimation. In contrast to traditional frequentist statistical methods, Bayesian analyses offer many benefits, including a richer description of the distribution of plausible parameter values given the data, the ability to easily quantify uncertainty in parameter estimates, and more intuitive inferential probability statements (see, e.g., Wagenmakers, Morey, \& Lee, 2016; Kruschke \& Liddell, 2018). Bayesian analysis involves the re-allocation of credibility across possible parameter values of a descriptive model of data, employing Bayes' rule to update the prior credibility of parameter values (prior distribution) after collecting observed data (posterior distribution) (see, Kruschke \& Liddell, 2018). Thus Bayesian estimation allows us to infer what population-level learning myth endorsement rates could have credibly generated the observed data. All analyses reported in this paper used minimally informative prior distributions that are wide on the scale of the data, this means the priors contributed virtually no bias to the posterior distributions. Alternative prior choices did not appreciably change the estimates. For an introduction to Bayesian statistical methods, see the books by Kruschke (2015) and McElreath (2016).

All graphs and analyses were created and conducted with the statistical software $R(R$ Team, 2013). All contrast analyses were performed using a hierarchical Bayesian approach that is analogous to traditional single-factor analysis of variance (ANOVA) (see Kruschke, 2015, chp. 19). We summarize our findings with a point estimate indicating the most plausible 
parameter value and indicate uncertainty in this estimate with a $89 \%$ highest posterior density interval (HPDI) in brackets. The HPDI indicates the range of values containing the most credible $89 \%$ of parameters given the observed data. ${ }^{1}$ Thus the values contained within the HPDI have higher credibility than any values outside the HPDI, given the data. Traditional frequentist confidence intervals (CI) are commonly, and erroneously, interpreted as Bayesian HPDI intervals (see, Morey et al., 2016). We also display graphical summaries of important posterior distributions to help the reader to visualize the relative credibility of different parameter estimates and convey estimation uncertainty.

\section{Results}

Overall, the most credible estimate for the percentage of learning myths endorsed by instructional designers is $74 \%[70 \%, 78 \%]$ (see Figure 2). Thus despite the relatively small sample size, instructional designers are credibly expected to endorse greater than two-thirds of the queried learning myths.

\footnotetext{
${ }^{1}$ Why do we use a $89 \%$ credible interval rather than the conventional $95 \%$ interval? Given the arbitrariness of any interval selection, our intention is to obviate researchers' tendency to engage in unconscious hypothesis testing when presented with $95 \%$ intervals and focus attention instead on the shape and uncertainty communicated by the entire posterior distribution.
} 


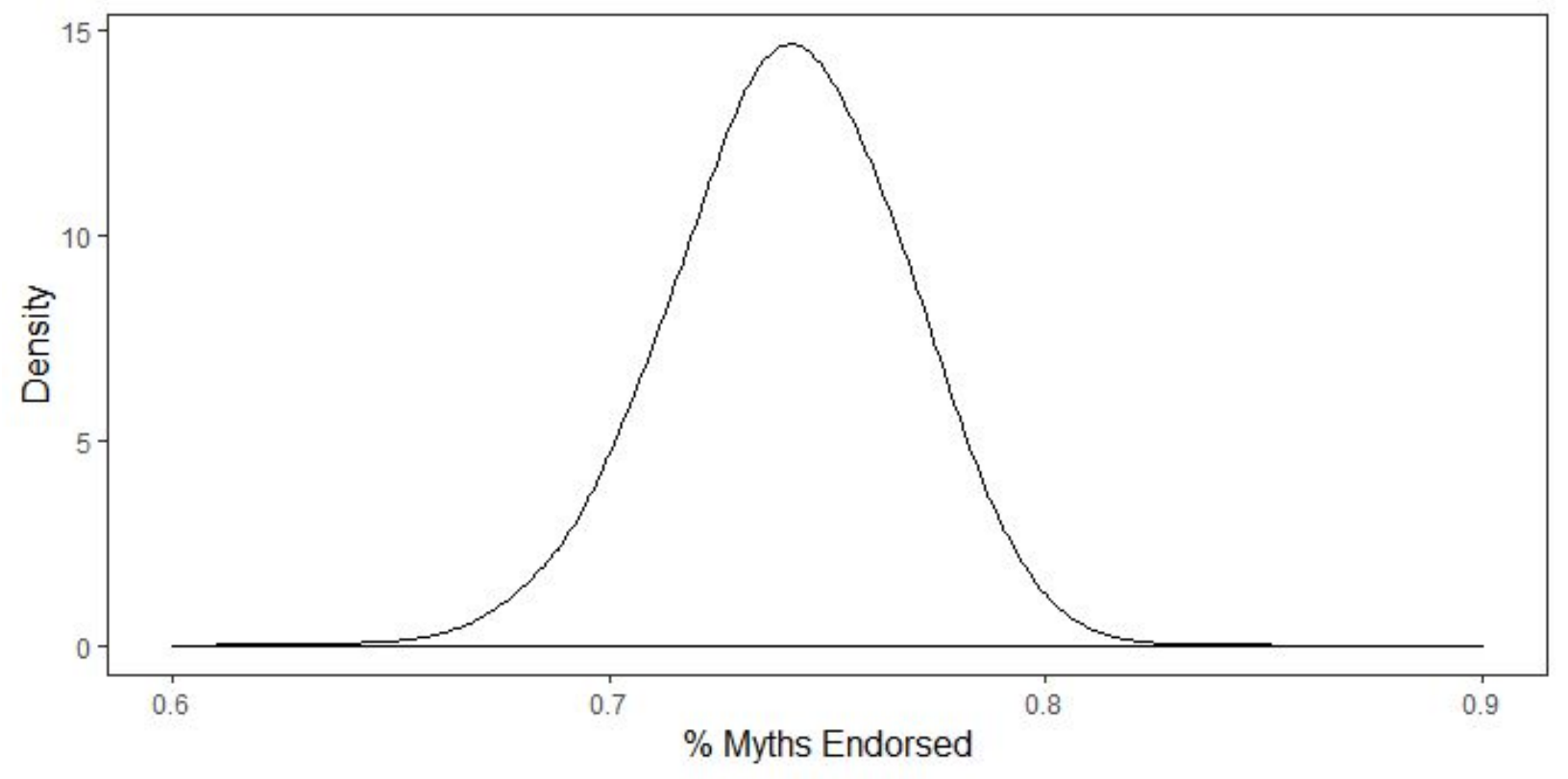

Figure 2. Posterior estimate for overall learning myth endorsement percentage among instructional designers. The $\mathrm{Y}$-axis values indicate the relative credibility of estimate parameters, with higher values being more plausible.

Table 1 shows that while all learning myths were endorsed by more than half of the IDs surveyed, there is notable variability in myth endorsement percentages. Both learning styles and multiple intelligences were endorsed by a considerable majority of participants, with learning styles supported by $86 \%$ of instructional designers and multiple intelligences theory endorsed by $80 \%$. Less likely to be endorsed were statements associated with the learning pyramid (73\%) and hemispheric dominance (60\%). Particularly interesting was the large number of instructional designers claiming to be not sure about learning myths compared with the percentage responding correctly, which never exceeds $17 \%$. Thus a lack of myth endorsement typically reflected a participant's uncertainty rather than knowledge of myth falsity. 
Table 1. Learning myth questions and participant response percentages.

\begin{tabular}{|c|c|c|c|}
\hline Learning Myth & Incorrect $\%$ & Correct \% & Not Sure \% \\
\hline $\begin{array}{l}\text { Individuals learn better when they receive information in their } \\
\text { preferred learning style (e.g., auditory, visual, kinesthetic). }\end{array}$ & 86 & 7 & 7 \\
\hline $\begin{array}{l}\text { Instruction should account for learners' multiple intelligence } \\
\text { types (e.g., mathematical, musical, naturalistic, etc.) through } \\
\text { differentiated teaching approaches. }\end{array}$ & 80 & 7 & 13 \\
\hline $\begin{array}{l}\text { Learners recall only } 10 \% \text { of what they've read and } 20 \% \text { of what } \\
\text { they see; however, they recall over } 75 \% \text { of what they actually } \\
\text { do. }\end{array}$ & 73 & 7 & 20 \\
\hline $\begin{array}{l}\text { Differences in hemispheric dominance (left brain, right brain) } \\
\text { can help explain learning differences amongst students. }\end{array}$ & 60 & 17 & 23 \\
\hline
\end{tabular}

For exploratory purposes, we also investigated several questions using the demographic information collected in the survey (see Table 2). For example, the survey revealed that many instructional designers did not possess degrees in instructional design or the related field of educational/instructional technology. Thus it might be wondered whether instructional designers with degrees outside of these disciplines, whose educational backgrounds are less likely to include content in the learning sciences, would be more inclined to endorse learning myths. 
Table 2. Learning myth endorsement estimates. Point estimates [and 89\% HPDIs] are presented for the overall estimate and each demographic breakdown.

\% Learning Myths Endorsed

\begin{tabular}{lr}
\hline Overall & $74 \%[69 \%, 78 \%]$ \\
Highest Degree & \\
Education & $75 \%[67 \%, 78 \%]$ \\
Instructional Design & $72 \%[64 \%, 79 \%]$ \\
Instructional/Educational Tech & $77 \%[70 \%, 83 \%]$ \\
Other & $74 \%[68 \%, 80 \%]$ \\
Professional Experience & $81 \%[68 \%, 91 \%]$ \\
Less than 2 years & $76 \%[68 \%, 83 \%]$ \\
2-5 years & $80 \%[75 \%, 84 \%]$ \\
5-15 years & $41 \%[27 \%, 55 \%]$ \\
More than 15 years & \\
Post-Secondary Teaching Exp & $70 \%[64 \%, 75 \%]$ \\
Yes & $82 \%[75 \%, 87 \%]$ \\
No & \\
Keep Up on Learning Research? & $-{ }^{\mathrm{a}}$ \\
None & $68 \%[57 \%, 77 \%]$ \\
A Little & $80 \%[75 \%, 86 \%]$ \\
Somewhat & $68 \%[59 \%, 75 \%]$ \\
A Lot &
\end{tabular}

${ }^{\mathrm{a}}$ No participants reported not keeping up on learning research at all.

Figure 3 displays boxplots of instructional designer degree categories, providing a visual comparison of the different percentages of myths endorsed by each group. The graph suggests myth endorsement percentages were relatively consistent across degree groups. Contrast analyses comparing endorsement percentages between groups confirmed this judgment, with no credible differences among degree earners. 


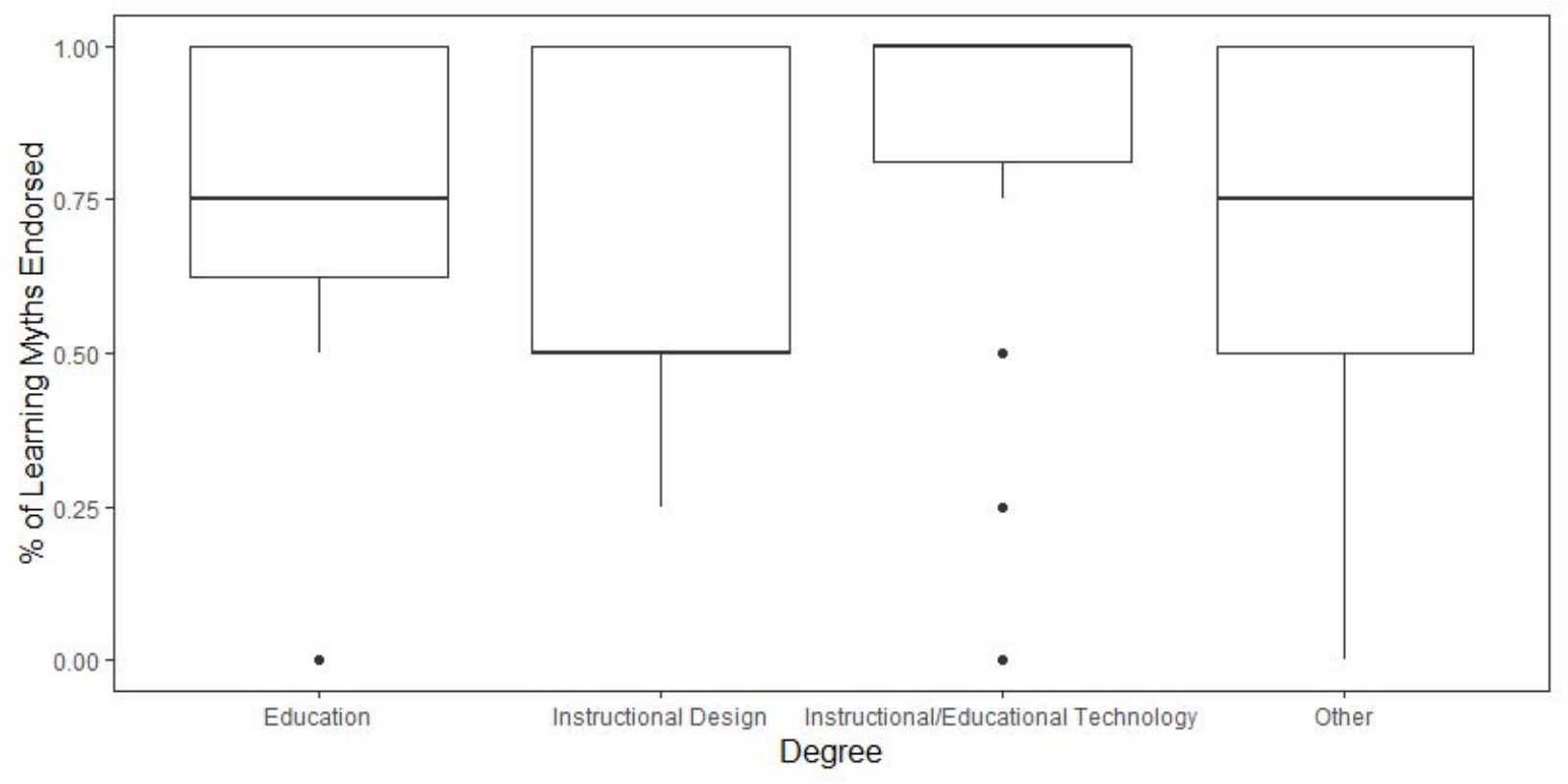

Figure 3. Percentage of learning myths endorsed given instructional designers' highest degree earned.

Exploratory analyses also investigated the impact of instructional designers' years of experience. Figure 4 displays boxplots of the four experience level categories. The graph shows instructional designers with more than 15 years of experience tended to endorse fewer myths than the other groups. Using a hierarchical Bayesian approach to examine relevant contrasts, analyses revealed that instructional designers in groups with less than 15 years of experience did not credibly differ from each other, with parameter estimates of group differences all overlapping zero. However, instructional designers with more than 15 years of experience credibly differed from the other groups in the number of learning myths endorsed. 


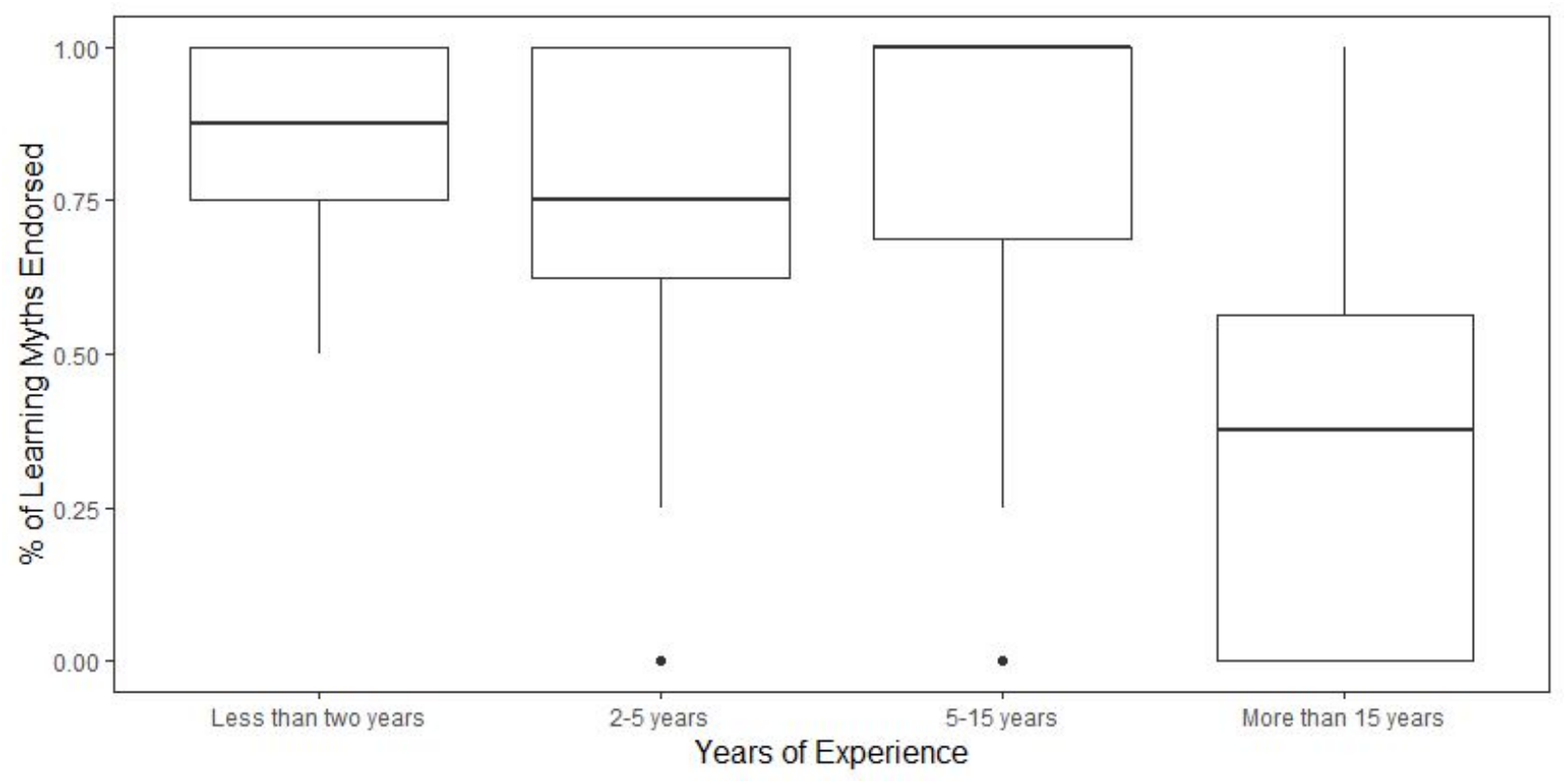

Figure 4. Percentage of learning myths endorsed given instructional designers' years of experience.

As seen in Figure 5, the posterior distribution of credible differences between instructional designers with more or less than 15 years of experience shows, on average, a $36 \%$ $[20 \%, 54 \%]$ lower myth endorsement percentage among instructional designers with more than 15 years of experience. While this finding suggests the difference between the observed means is credibly different from zero, there is large uncertainty due to the small number of instructional designers in the survey who had worked more than 15 years. Thus these results should be interpreted only as indicative and are potentially substantial overestimates (see, Gelman \& Carlan, 2014). 


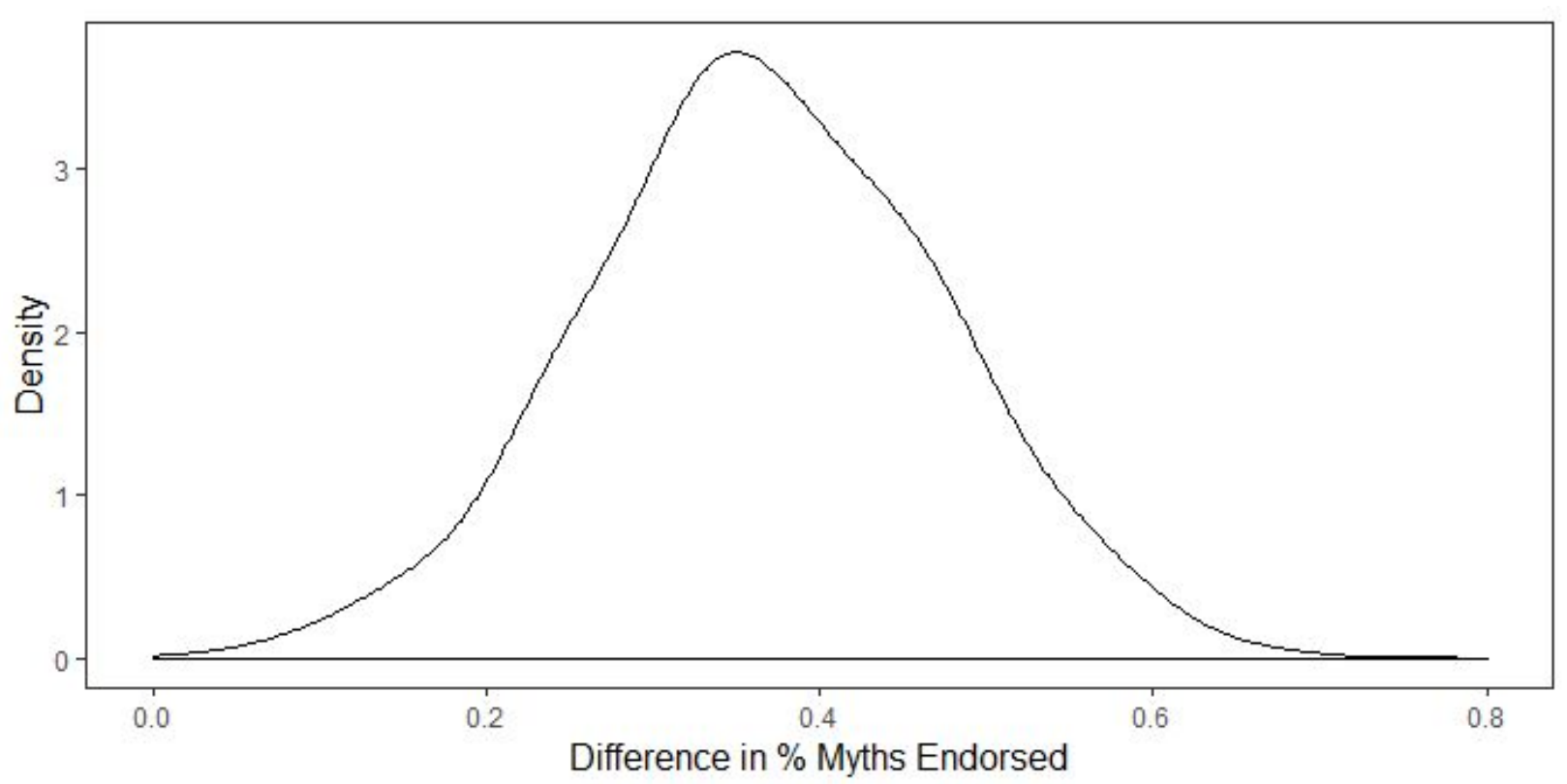

Figure 5. Posterior estimates for the difference in learning myth endorsement percentage between instructional designers with more or less than 15 years of experience. The $\mathrm{Y}$-axis values indicate the relative credibility of estimate parameters, with higher values being more plausible.

Finally, we examined whether there were any credible differences in learning myth endorsement percentages given instructional designers' responses to how current they keep up on learning research as well as whether they had post-secondary teaching experience. Follow-up contrast analyses found no credible differences in learning myth endorsement percentages based on instructional designers' responses to research; however, comparisons between instructional designers who had post-secondary teaching experience and those who didn't, revealed a credible difference in learning myth endorsement estimates, with instructional designers who lacked post-secondary teaching experience estimated to endorse $11 \%[3 \%, 20 \%]$ more myths. Again, these results should be interpreted as merely indicative and exploratory in nature. 


\section{Discussion}

\section{The Enduring Popularity of Learning Myths}

Overall, this study suggests slightly lower learning myth endorsement levels among instructional designers compared with previously surveyed educators and student teachers (Ferrero et al., 2016). While this is encouraging, belief in learning myths is still alarmingly high and roughly half of all surveyed instructional designers endorsed all four myths. Our pattern of findings also mirror the endorsement trends of previous research, with belief in learning styles notably outpacing other all other learning myths (see e.g., Deligiannidi and Howard-Jones, 2015; Karakus et al., 2015; Pei et al., 2015). This finding is particularly discouraging given the concerted and highly public efforts among researchers and academics to debunk myths like learning styles (e.g., Hood et al., 2017). Furthermore, even for those myth statements with lower endorsement levels, instructional designers were far more likely to respond with 'not sure' than to answer correctly. It is clear that those of us hoping to purge education of learning myths, in favor of more evidence-informed practices, still have much work ahead.

So what explains the enduring popularity of learning myths in education? There are no doubt many contributing factors. Education has always been susceptible to fads and innovative-sounding ideas that promise simple, fun, and quick ways to improve student outcomes. As Slavin (2008) notes, in education the "[...] adoption of instructional programs and practices has been driven more by ideology, faddism, politics, and marketing than by evidence" (p. 5). Educators are also frequently targeted for learning myth propaganda by commercial interests (e.g., Goswami, 2006), and these myths pervade professional organizations targeting instructional designers as well. For example, a brief perusal of the popular instructional design 
website elearningindustry.com reveals numerous articles on the benefits of tailoring instruction to students' learning styles or multiple intelligences, and the journals associated with the International Society for Technology in Education (ISTE) continue to publish articles endorsing the educative value of learning styles theory.

Furthermore, as Coffield et al. (2004) observe, the sheer volume of articles in the scholarly literature on myths like learning styles gives the impression that these topics are areas of productive research, although a closer examination reveals few studies to be scientifically credible. As a result, an instructional designer who is skeptical of a theory like learning styles, and endeavors to explore the available literature to assess the theory's empirical status, is likely to walk away with a deeply misguided impression (see Newton, 2015). A quick Google Scholar search by the present author on the key phrase "learning styles," for instance, revealed that 17 of the first 20 results were articles or citations supportive of the value of learning styles theory in education; a similar ratio of myth endorsing articles was observed after entering the keywords "multiple intelligences education."

Finally, it has been suggested that the persistence of learning myths can be partially attributed to human cognitive biases (Pasquinelli, 2012; Willingham, Hughes, \& Dobolyi, 2015). Many learning myths may resist debunking because educators and instructional designers are inclined to focus on anecdotal information and personal experiences that confirm their beliefs while discounting scholarly critiques, a phenomenon known as confirmation bias (Nickerson, 1998). 


\section{From Learning Myths to Learning to Listen}

So what can we do to better combat learning myths in education? A popular suggestion is to increase the scientific and neuro-literacy among teachers and others involved in education (e.g., Dekker et al., 2012; Papadatou-Pastou et al., 2017). And while we agree there is value in this strategy, several studies have found that increasing educators' exposure to scientific thinking improves neuroscience literacy but does not meaningfully reduce susceptibility to learning myths (Im, Cho, Dubinsky, \& Varma, 2018; Weisberg, Keil, Goodstein, Rawson, \& Gray, 2008). And recent surveys suggest even individuals with high neuroscience exposure, those possessing college or graduate degrees in science-related fields, still endorse popular learning myths at shockingly high levels (Macdonald et al., 2017).

Others have called for greater collaboration among educational practitioners and researchers, as well as greater efforts to translate research findings in ways that non-specialists can access (Howard-Jones, 2014). Again, we agree these ideas have promise but believe that successfully uprooting learning myths ultimately requires a better understanding of why these myths remain so attractive in education. To that end, we conclude this article with observations that we've gleaned from numerous follow-up discussions with educators and instructional designers regarding the enduring appeal of the learning myths discussed in this article.

One distinguishing feature of education is how value-laden it is. We've found that effective instructional strategies are often resisted or rejected because they are associated with a particular philosophy regarding the nature of children and the role of education in society. For example, there is substantial evidence that instruction incorporating frequent retrieval practice 
and spaced repetition engenders robust learning gains (see, Dunlosky, Rawson, Marsh, Nathan, \& Willingham, 2013); however, many educators may demur from these techniques because they are perceived as aligning with teaching methods focused on rote learning or endorsing a 'manufacturing perspective' of education. Analogously, because most educators are deeply committed to the ideals of inclusion and diversity, popular learning myths that appear to embrace student individuality are intuitively attractive despite the absence of empirical support. In fact, many of the educators and instructional designers we've talked with have explicitly stated that their sympathy for theories like learning styles and multiple intelligences is largely attributable to the fact that these theories reflect their deep commitment to respecting student uniqueness. In no small part, these myths are attractive because they convey the sanguine message that no student is better or worse than any other, and that every student can learn equally well if only taught in accordance with his or her preferred thinking or learning style (Lilienfeld, Lynn, Ruscio, \& Beyerstein, 2011). And myths like the learning pyramid, which reflect many educators' antipathy for traditional information transmission models of teaching in favor of instructional methods that encourage student inquiry and self-discovery, are also ideologically seductive for these philosophical reasons. It is not unexpected, therefore, to find that education is rife with 'eduquacks' who prey on educator and public sympathies by profering romanticized educational solutions based on eminence and emotion rather than evidence (see Kirschner \& Neelen, 2017). Belief in myths like learning styles and the learning pyramid may therefore reflect an ideological rather than scientific decision for many educators.

If these observations capture at least some of the motivations of educators and instructional designers--and there should be more systematic research to investigate this 
conjecture--then the continued failure of efforts to debunk popular learning myths is not surprising. We cannot expect to convince educators to abandon popular learning myths by focusing simply on their lack of empirical evidence and eschewing the more fundamental philosophical and ideological values that make them so attractive.

So what might a more successful strategy for challenging learning myths look like? On the one hand, it is important to acknowledge and validate educators' laudable commitments to embracing student diversity and personal agency. And rather than merely debunking popular learning myths, we should proactively offer empirically supported alternatives that align with these core values. As Pershan and Riley state, "It is better to replace ideas than debunk them" (2017). For instance, we need to better communicate research findings regarding student differences that demonstrably matter when it comes to learning-- e.g., differences in prior knowledge, motivation, learning strategies, interest, and effort (see Bjork, 2011). Responsiveness to student difference is critical for education, but we need to personalize instruction in ways known to positively impact student learning rather than endorse dubious categorizations in a misguided pursuit of greater inclusivity. And rather than simply rejecting the universal superiority of participatory teaching methods, as falsely suggested by the learning pyramid, researchers should emphasize the importance of embedding student inquiry and discovery within a directed and scaffolded instructional sequence (e.g., see, Kirschner, Sweller, \& Clark, 2006; Merriënboer \& Kirschner, 2017). Students should have opportunities to discover ideas, work with real-world problems, and fully participate in their educational experiences, but we should aid their exploration in ways that decades of education research suggest are likely to be most rewarding and efficacious. Respecting student individuality and autonomy in teaching, while 
also incorporating instructional practices known to be effective for all students, will always be a challenging balancing act (see Willingham et al., 2015), but we owe it to students to design educational experiences informed by the best available empirical evidence.

On the other hand, we also need to do a better job pointing out that despite the superficial embrace of student individuality promised by many popular learning myths, these theories are often counterproductive when it comes to advancing the goals of inclusion and diversity. In particular, the dubious categorizations entailed by these theories can pigeon-hole and stereotype students-- creating artificial labels and pernicious lists of strengths/weaknesses-- that can stigmatize learners and lead to self-fulfilling prophecies (e.g., "I don't learn well from reading."). Adopting these learning myths may also lead to poor teaching strategies that depress learning for students (Willingham et al., 2015). Even currently popular ideas like growth mindset and grit can have the unintended side effect of labeling students and encouraging instructors to erroneously essentialize learners as being of a certain 'type' if we aren't careful, overlooking the fact that these labels will invariably evolve over time and perhaps change dramatically in different contexts or settings.

\section{Conclusion}

Although the findings reported here are limited in scope, involving a small sample of practicing instructional designers in the United States, the results are both robust and consistent with previous findings. Although more research is needed to understand the attraction and pervasiveness of learning myths among instructional designers, the findings reported here continue a worrying trend. The popularity and widespread endorsement of learning myths in education is troubling for many reasons. Most notably, it encourages schools, educators, and 
designers of instruction to waste valuable time, effort, and money on unsubstantiated interventions, commercial programs, and instructional strategies that could instead be devoted to implementing evidence-informed practices and embracing student diversity in demonstrably effective ways. And despite the well-meaning efforts of educators and instructional designers, acceptance of these myths may unintentionally harm the very students they want to help, denying students learning experiences informed by the best available evidence.

It's increasingly clear there is no quick fix when it comes to eliminating learning myths in education. However, listening and seeking to understand the pedagogical motivations of educators and instructional designers, and responding with evidence-informed alternatives that align with these values, may be the most effective strategy to convince those in education to abandon ideologically attractive, but empirically unsubstantiated, learning myths. 


\section{References}

Armstrong, T. (2009). Multiple intelligences in the classroom, 3rd edition. Alexandria,VA: Association for Supervision and Curriculum Development.

Bjork, R. A. (2011). On the symbiosis of remembering, forgetting, and learning. In Successful remembering and successful forgetting (pp. 19-40). Psychology Press.

Bjork, R. A., Dunlosky, J., \& Kornell, N. (2013). Self-regulated learning: beliefs, techniques, and illusions. Annual Review of Psychology, 64, 417-44.

http://doi.org/10.1146/annurev-psych-113011-143823

Boser, Ulrich (2017) What do people know about excellent teaching and learning? Center for American Progress Report. Retrieved from:https://cdn.americanprogress.org/content/uploads/2017/03/10122018/TeachingAndLear ning-brief.pdf

Clark, R., \& Mayer, R. (2008). Learning by viewing versus learning by doing: Evidence-based guidelines for principled learning environments. Performance Improvement, 47(9), 5-13. https://doi.org/10.1002/pfi.20028

Coffield, F., Moseley, D., Hall, E., \& Ecclestone, K. (2004). Should we be using learning styles? What research has to say to practice. Learning \& Skills Research Centre.

Corballis, M. C. (2007). The dual-brain myth. Tall tales on the brain (ed. S. Della Sala), 291-313. Oxford: Oxford University Press.

Dandy, K. L., \& Bendersky, K. (2014). Student and Faculty Beliefs About Learning in Higher Education: Implications for Teaching. International Journal of Teaching and Learning in Higher Education, 26, 358-380. 
De Bruyckere, P., Kirschner, P. A., \& Hulshof, C. D. (2015). Urban myths about learning and education. Academic Press.

Dekker, S., Lee, N. C., Howard-Jones, P., \& Jolles, J. (2012). Neuromyths in education: Prevalence and predictors

of misconceptions among teachers. Frontiers in Psychology, 3, 429. https://doi.org/10.3389/fpsyg.2012.00429

Deligiannidi, K., and Howard-Jones, P. A. (2015). The neuroscience literacy of teachers in Greece. Procedia - Social and Behavioral Sciences, 174, 3909-3915. doi: 10.1016/j.sbspro.2015.01.1133

Dunlosky, J., Rawson, K. A., Marsh, E. J., Nathan, M. J., \& Willingham, D. T. (2013). Improving Students' Learning With Effective Learning Techniques: Promising Directions From Cognitive and Educational Psychology. Psychological Science in the Public Interest, 14(1), 4-58. http://doi.org/10.1177/1529100612453266

Ferrero, M., Garaizar, P., \& Vadillo, M. A. (2016). Neuromyths in Education: Prevalence among Spanish Teachers and an Exploration of Cross-Cultural Variation. The Journal of Frontiers Human Neuroscience, 10, 496. https://doi.org/10.3389/fnhum.2016.00496

Gardner, H. (1983). Frames of mind: The theory of multiple intelligences. New York: Basic Books.

Gardner, H. (2013). Frequently asked questions-- what are the major educational implications of the theory? [FAQ] Retrieved from https://howardgardner01.files.wordpress.com/2012/06/faq_march2013.pdf 
Geake, J. (2008). Neuromythologies in education. Educational Research, 50(2), 123-133. http://doi.org/10.1080/00131880802082518

Gelman, A., \& Carlin, J. (2014). Beyond Power Calculations: Assessing Type S (Sign) and Type M (Magnitude) Errors. Perspectives on Psychological Science, 9, 641-651. http://doi.org/10.1177/1745691614551642

Gleichgerrcht, Z., Luttges, B. L., Salvarezza, F., \& Campos, A. L. (2015). Educational Neuromyths among Teachers in Latin America. Mind, Brain, and Education, 9(3), 170-178. https://doi.org/10.1111/mbe.12086

Goswami, U. (2006). Neuroscience and education: From research to practice? Nature Reviews Neuroscience, 7, 406-413. https://doi.org/10.1038/nrn1907

Hood, B., Howard-Jones, P., Laurillard, D., Bishop, D., Coffield, F., Uta Frith, D., ..., Foulsham, T. (2017, March 12). No evidence to back the theory of learning styles [Letter to the editor]. The Guardian. Retrieved from:

https://www.theguardian.com/education/2017/mar/12/no-evidence-to-back-idea-of-learning-s tyles

Hoffman, E. (2002). Introducing children to their amazing brains. LTL Books.

Howard-Jones, P. A. (2014). Neuroscience and education: Myths and messages. Nature Reviews Neuroscience, 15, 817-824. https://doi.org/10.1038/nrn3817

Im, S. H., Cho, J. Y., Dubinsky, J. M., \& Varma, S. (2018). Taking an educational psychology course improves neuroscience literacy but does not reduce belief in neuromyths. PLoS ONE, 13(2), 1-19. 
Karakus, O., Howard-Jones, P. A., and Jay, T. (2015). Primary and secondary school teachers' knowledge and misconceptions about the brain in Turkey. Procedia-Social and Behavioral Sciences, 174, 1933-1940. doi: 10.1016/j.sbspro.2015. 01.858

Karpicke, J. D., Butler, A. C., \& Roediger, H. L. (2009). Metacognitive strategies in student learning: Do students practise retrieval when they study on their own? Memory, 17, 471-9. http://doi.org/10.1080/09658210802647009

Kirschner, P. A. (2017). Stop propagating the learning styles myth. Computers \& Education, 106, 166-171. http://doi.org/10.1016/j.compedu.2016.12.006

Kirschner, P.A. \& Neelen, M. (2017, September 19). Eminence-Based Education or the Terror of Famous and Shameless Eduquacks. [Blog post]. Retrieved from:

https://3starlearningexperiences.wordpress.com/2017/09/19/eminence-based-education-or-th e-terror-of-famous-shameless-eduquacks/

Kirschner, P. A., Sweller, J., \& Clark, R. E. (2006). Why Minimal Guidance During Instruction Does Not Work: An Analysis of the Failure of Constructivist, Discovery, Problem-Based, Experiential, and Inquiry-Based Teaching. Educational Psychologist, 41(2), 75-86. https://doi.org/10.1207/s15326985ep4102_1

Kirschner, P. A., \& van Merriënboer, J. J. G. (2013). Do Learners Really Know Best? Urban Legends in Education. Educational Psychologist, 48 (3), 169-183. http://doi.org/10.1080/00461520.2013.804395

Kruschke, J. (2015). Doing Bayesian data analysis: A tutorial with R, JAGS, and Stan, 2nd Edition. Academic Press. 
Kruschke, J. K., \& Liddell, T. M. (2018). The Bayesian New Statistics: Hypothesis testing, estimation, meta-analysis, and power analysis from a Bayesian perspective. Psychonomic Bulletin \& Review, 25, 178-206. https://doi.org/10.3758/s13423-016-1221-4

Kornell, N., \& Bjork, R. A. (2007). The promise and perils of self-regulated study. Psychonomic Bulletin \& Review, 14, 219-24. https://doi.org/10.3758/BF03194055

Kornhaber, M., Fierros, E., \& Veenema, S. (2004). Multiple intelligences: Best ideas from research and practice. Boston, MA: Pearson Education.

Lalley, J., \& Miller, R. (2007). The learning pyramid: Does it point teachers in the right direction. Education, 128(1), 64-79.

Letrud, K. (2012). A Rebuttal of NTL Institute's Learning Pyramid. Education, 133(1), 117-124.

Lilienfeld, S. O., Lynn, S. J., Ruscio, J., \& Beyerstein, B. L. (2011). 50 great myths of popular psychology: Shattering widespread misconceptions about human behavior. John Wiley \& Sons.

Macdonald, K., Germine, L., Anderson, A., Christodoulou, J., \& McGrath, L. M. (2017). Dispelling the myth: Training in education or neuroscience decreases but does not eliminate beliefs in neuromyths. Frontiers in Psychology, 8, 1314. https://doi.org/10.3389/fpsyg.2017.01314

McElreath, R. (2016). Statistical rethinking: A Bayesian course with examples in R and Stan. Boca Raton, FL: Chapman \& Hall/CRC.

Morey, R. D., Hoekstra, R., Rouder, J. N., Lee, M. D., \& Wagenmakers, E.-J. (2016). The fallacy of placing confidence in confidence intervals. Psychonomic Bulletin \& Review, 23(1), 103-123. http://doi.org/10.3758/s13423-015-0947-8 
Van Merriënboer, J. J., \& Kirschner, P. A. (2017). Ten steps to complex learning: A systematic approach to four-component instructional design. Routledge.

Meyer K. A., Murrell V. S. (2014). A National Study of Theories and Their Importance for Faculty Development for Online Teaching. Online Journal of Distance Learning Administration, (17), 2. Available at: http://www.westga.edu/ distance/ojdla/summer172/Meyer Murrell172.html

Nickerson, R. S. (1998). Confirmation bias: A ubiquitous phenomenon in many guises. Review of General Psychology, 2, 175-220.

Nielsen, J. A., Zielinski, B. A., Ferguson, M. A., Lainhart, J. E., \& Anderson, J. S. (2013). An evaluation of the left-brain vs. right-brain hypothesis with resting state functional connectivity magnetic resonance imaging. PloS one, 8(8), e71275. https://doi.org/10.1371/journal.pone.0071275

Newton, P. M. (2015). The Learning Styles Myth is Thriving in Higher Education. Frontiers in Psychology, 6, 1908. https://doi.org/10.3389/fpsyg.2015.01908

Papadatou-Pastou, M., Haliou, E., \& Vlachos, F. (2017). Brain knowledge and the prevalence of neuromyths among prospective teachers in Greece. Frontiers in Psychology, 8, 804. http://doi.org/10.3389/fpsyg.2017.00804

Pasquinelli, E. (2012). Neuromyths: Why Do They Exist and Persist? Mind, Brain, and Education, 6(2), 89-96. http://doi.org/10.1111/j.1751-228X.2012.01141.x

Pashler, H., McDaniel, M., Rowher, D., \& Bjork, R. (2009). Learning styles: Concepts and evidence. Psychological Science in the Public Interest, 9(3), 105-119. https://doi.org/10.1111/j.1539-6053.2009.01038.x 
Pei, X., Howard-Jones, P. A., Zhang, S., Liu, X., and Jin, Y. (2015). Teacher's understanding about the brain in East China. Procedia - Social and Behavioral Sciences, 174, 3681-3688. doi: 10.1016/j.sbspro.2015.01.1091

Pershan, M. \& Riley, B. (2017). Why mythbusting fails: a guide to influencing education with science [Blog post]. Retrieved from:

https://deansforimpact.org/why-mythbusting-fails-a-guide-to-influencing-education-with-scie nce/

Pomerance, L., Greenberg, J., \& Walsh, K. (2016). Learning about Learning: What Every New Teacher Needs to Know. National Council on Teacher Quality.

R Core Team (2013). R: A language and environment for statistical computing. R Foundation for Statistical Computing, Vienna, Austria. URL http:/www.R-project.org/.

Rato, J. R., Abreu, A. M., \& Castro-Caldas, A. (2013). Neuromyths in education: what is fact and what is fiction for Portuguese teachers? Educational Research, 55, 441-453. http://doi.org/10.1080/00131881.2013.844947

Shore, R. (2017). Left brains, learning styles, and who cares what time it is? Journal of Applied Educational and Policy Research, 3(1), 105-107.

Siegel, D. J., \& Bryson, T. P. (2012). The whole-brain child: 12 revolutionary strategies to nurture your child's developing mind. Bantam.

Slavin, R. E. (2008). Perspectives on evidence-based research in education: What works? Issues in synthesizing educational program evaluations. Educational Researcher, 37(1), 5-14. https://doi.org/10.3102/0013189X08314117 
Subramony, D., Molenda, M., Betrus, A., and Thalheimer, W. (2014). The Mythical Retention Chart and the Corruption of Dale's Cone of Experience. Educational Technology, 54(6), 6-16. Retrieved from http://www.jstor.org/stable/44430317

Tardif, E., Doudin, P. A., \& Meylan, N. (2015). Neuromyths among teachers and student teachers. Mind, Brain, and Education, 9(1), 50-59. https://doi.org/10.1111/mbe.12070

Weisberg, D. S., Keil, F. C., Goodstein, J., Rawson, E., and Gray, J. R. (2008). The seductive allure of neuroscience explanations. J. Cognitive Neuroscience, 20, 470-477. doi: 10.1162/jocn.2008.20040

Wagenmakers, E. J., Morey, R. D., \& Lee, M. D. (2016). Bayesian benefits for the pragmatic researcher. Current Directions in Psychological Science, 25(3), 169-176. https://doi.org/10.1177/0963721416643289

Waterhouse, L. (2006). Multiple intelligences, the Mozart effect, and emotional intelligence: A critical review. Educational Psychologist, 41, 207-225. https://doi.org/10.1207/s15326985ep4104_1

Willingham, D. T. (2004). Reframing the Mind. Education Next, 4(3), 19-24. Retrieved from: https://www.wtc.ie/images/pdf/Multiple_Intelligence/mi12.pdf

Willingham, D. T., Hughes, E. M., and Dobolyi, D. G. (2015). The scientific status of learning styles theories. Teaching of Psychology, 42, 266-271. doi: 10.1177/0098628315589505 